\title{
The pattern of cardiovascular manifestations in Egyptian Behçet's patients and its relation to disease activity
}

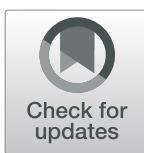

\author{
Nashwa Aly Morshedy ${ }^{1,2}$, Dalia Fayez Mohammed ${ }^{1,2}$, Fatma Mohammed Badr ${ }^{1,2}$ and \\ Mohammed Abd El monem Teama ${ }^{1,2^{*}}$ (i)
}

\begin{abstract}
Background: Behçet's disease (BD) is also referred to as vascular BD when it frequently involves the heart and vessels. This study aimed to describe the cardiovascular manifestations in patients with BD and its correlation to disease activity. We conducted a cross-sectional study on 40 patients diagnosed with BD according to the International Criteria for Behçet's Disease 2014. All the patients were subjected to detailed history taking, full clinical examination, lab investigations, resting electrocardiogram, trans-thoracic echocardiography, and carotid artery duplex for measuring intimal thickness, peripheral arterial and venous duplex, computed tomography pulmonary angiography, and full ophthalmological examination. Regarding the activity of the disease, it was assessed according to the score of Behçet's Disease Current Activity Form (BDCAF).

Results: The most common cardiac manifestation was valvular lesion (67.5\%) where the most frequently affected valve was the tricuspid valve (27.5\%). Although $25 \%$ of patients had left ventricular diastolic dysfunction, only $5 \%$ had intracardiac masses. Approximately $52.5 \%$ of patients had vascular lesion (deep venous thrombosis $45 \%$, arterial involvement 7.5\% [as pulmonary artery thrombosis 5\% and aneurysm 2.5\%]). Increase in intima media thickness (IMT) was observed in $7.5 \%$ of patients, while $60 \%$ had abnormal lipid profiles. Hypercholesterolemia was the most common lipid abnormality (50\%). BDCAF score range was 4-12, which was significantly correlated to multiple cardiovascular parameters as a mitral, tricuspid valve, and vascular venous involvement $(p<0.05)$, while not significantly correlated to lipid profile $(p>0.05)$.
\end{abstract}

Conclusion: Cardiovascular complications are frequent among patients with $\mathrm{BD}$, even those who are asymptomatic; therefore, these complications must be screened for early detection and proper management.

Keywords: Behçet's disease, Cardiovascular manifestations, Lipid profile, Disease activity score

\footnotetext{
* Correspondence: mohteama2009@yahoo.com

'Internal Medicine, Rheumatology and Immunology Faculty of Medicine, Ain Shams University, El Al Waili / El-Abaseya, Cairo 11517, Egypt

${ }^{2}$ Faculty of Medicine, Ain Shams University, Ramsis Street, Abbassia Square, Cairo, Egypt
} 


\section{Background}

Behçet's disease (BD) is a systemic vasculitis of uncertain etiology characteristically affecting blood vessels. It is diagnosed clinically by recurrent oral and/or genital aphthosis, mucocutaneous lesions, central nervous system manifestation, and ocular, vascular, articular, gastrointestinal, inflammatory eye lesions and tendency for thrombosis in young adults; however, diagnosis may be challenging. Treatment is difficult and should be individualized [1].

Cardiac involvement in $\mathrm{BD}$ is variable and is thought to occur in the range of $7-46 \%$ [2]. Moreover, it was obsereved that both cardiac and arterial complications are also important aspects of the course of the disease. Cardiac lesions that have been reported in the literature include pericarditis, endocarditis, intracardiac thrombosis, myocardial infarction, endo-myocardial fibrosis, and myocardial aneurysm [3-5]. Treatment of cardiovascular involvement in $\mathrm{BD}$ is towards suppressing vasculitis [6].

Different types of vessels, predominantly veins, can be affected in BD. The frequency of vascular lesions in BD, such as superficial and deep venous thromboses, arterial aneurysms, and occlusions, ranges between 7-29\% [7]. Diffrient factors of thrombogenesis in BD are presented and discussed from positions of Virchow's triad of venous thrombosis, particularly, pro- and antithrombotic endothelial and non-endothelial factors, factors of coagulation, and platelet activation [8].

BD has increased mortality specially among young males, while being not as severe as seen in females and old patients. Usually, the disease severity decreases with time. However, large-vessel vascular disease is considered as the most important cause of mortality in $\mathrm{BD}$, particularly hemorrhage owing to pulmonary artery aneurysms [9].

Different Egyptian studies describe cardiovascular manifestations in BD [10-12]; however, the current study focused on both cardiac and vascular spectrum in BD patients in a Egyptian cohort and correlated them to disease activity.

The present study aimed to describe cardiovascular manifestations in patients with $\mathrm{BD}$ and its correlation to disease activity

\section{Methods}

\section{Patients}

We conducted a cross-sectional study with 40 patients who were diagnosed with $\mathrm{BD}$ according to the International Criteria for Behçet's Disease (ICBD) [13] aged 18-60 years, recruited from the Ain Shams University Hospital. We excluded patients with other associated autoimmune diseases, smokers, obese individuals (body mass index $\geq 30$ ), and hypertensives or diabetics. We recruited patients from April 2019 to March 2020.

\section{Ethical considerations}

This study was conducted according to the criteria mentioned in the World Medical Association's Declaration of Helsinki in October 2013. We obtained informed consent from each patient after demonstrating study's aim and procedures. The local ethical committee of Ain Shams University approved our study protocol.

\section{Clinical evaluation}

Detailed history was obtained from all the patcipants including their age, sex, disease duration, and full clinical examination with special emphasis on signs and symptoms of BD.

\section{Laboratory investigations}

Laboratory investigations were done for all the patients including complete blood count $(\mathrm{CBC})$, erythrocyte sedimentation rate (ESR), kidney function tests (serum creatinine, blood urea nitrogen (BUN), C-reactive protein (CRP) with titer, liver enzyme alanine aminotransferase (ALT), (aspartate aminotransferase (AST), lipid profile including low-density lipoprotein (LDL)-C, highdensity lipoprotein cholesterol (HDL-C), triglycerides, and total cholesterol (a total cholesterol of $>240 \mathrm{mg} / \mathrm{dl}$ has been classified as elevated; triglyceride levels > 200 $\mathrm{mg} / \mathrm{dL}$ have been classified as elevated; low HDL-C has been classified as $<40 \mathrm{mg} / \mathrm{dL}$ in men, and $<50 \mathrm{mg} / \mathrm{dL}$ in women; an LDL-C value $>160 \mathrm{mg} / \mathrm{dL}$ has been classified as high) [14].

\section{Disease activity assessment}

Disease activity was determined according to the score of Behçet's Disease Current Activity Form (BDCAF) [15]. To calculate the BDCAF score, the presence of each general item accounts for one mark. The presence of any eye, neurological, or major vessel affection takes one mark as a whole even if all signs are present; therefore, the score is out of 12 .

\section{Imaging investigations Echocardiography}

All patients were examined with Philips iE33 echocardiographic machine (Philips Medical Systems, Andover, MA, USA). A broadband $2.5-3.5 \mathrm{MHz}$ phased array transducer equipped with tissue Doppler imaging (TDI) mode was used. Two-dimensional imaging (2D) was performed, followed by Doppler. A single investigator had performed transthoracic echocardiography (ECHO) for $>5$ years and had achieved level 3 training in echocardiography from cardiology department at Ain Shams University who was blinded to patient data. 


\section{Echocardiographic analysis}

Two-dimensionally guided M-mode tracings were obtained from the parasternal short-axis view to measure the left ventricular (LV) dimensions and wall thickness. The LV ejection fraction (EF) was measured using the disk summation method. According to the guidelines from the American Society of Echocardiography (ASE), an $\mathrm{EF}<55 \%$ was considered abnormal [16].

To assess the LV diastolic function, the following Doppler parameters were measured: peak E velocity, peak A wave velocity, E/A ratio, and deceleration time of $\mathrm{E}$ velocity. Using the tissue Doppler imaging (TDI), the lateral mitral annular E'-wave velocity was obtained, and the E/ E' ratio was then calculated [17].

For assessment of the right ventricular (RV) systolic functions, the fractional area change (FAC), the tricuspid annular plane systolic excursion (TAPSE), and $\mathrm{S}$ wave velocity of the lateral tricuspid annulus were measured and analyzed according to the guidelines published by the ASE in 2010 [18].

The cardiac valves were assessed by $2 \mathrm{D}$, color, and Doppler imaging. The severity of the aortic regurgitation was assessed by measurement of the vena contracta width as well as the proximal jet width obtained from the parasternal long-axis view and its ratio to the LV outflow tract diameter (LVOT). A ratio of proximal jet width to the LVOT diameter $>65 \%$ with a VC $>0.6 \mathrm{~cm}$ defined severe aortic regurgitation.

Detected pericardial effusion (PE) was described according to its amount, site, associated fibrinous shreds, and evidence of increased intrapericardial pressure. Severe PE was defined as an echo-free space of $\geq 1 \mathrm{~cm}$ seen surrounding the heart. Detected intracardiac masses were fully analyzed regarding their location, number, size, texture, and mobility. Other measurements were assesed as left ventricular end-systolic diameter, left ventricular end-diastolic diameter, interventricular septum diameter, left atrial diameter, pulmonary artery pressure, and right ventricular systolic diameters.

\section{Cartoid artery duplex}

All patients underwent two-dimensional echo-color Doppler of the carotid arteries, adopting a high definition vascular echographic apparatus Philips Sonos 5500 Bothell (Washington, USA) and a $10-3 \mathrm{MHz}$ linear electronic probe. During the procedure, patients were placed in a supine position, with the neck extended and turned, contralaterally by about 45 with a probe placed over the common carotid artery on both sides before carotid bifurcation with $1-2 \mathrm{~cm}$ for measuring IMT.

The intimal medial thickness was defined as the distance between the lumen-intima and media adventitia borders of the vessel, which was sonographically identified by a double hypoechoic line not projecting into the vessel lumen used for evaluation of the extent of carotid atherosclerotic vascular disease (cutoff value equal or greater than $1.1 \mathrm{~mm}$ ) [19]. A value of $0.74 \pm 0.14 \mathrm{~mm}$ was considered normal [20].

\section{Peripheral artrial and venous duplex}

Peripheral vascular arterial and venous duplexes were conducted where Doppler ultrasonography was performed in B-mode and color-mode spectral examinations using 13.5- and 9.4- $\mathrm{MHz}$ linear probes. The arterial and venous systems for both the upper and lower extremities were examined for venous insufficiency, thrombosis, arterial stenosis, and aneurysm. The venous insufficiency was determined by the presence of valvular incompetence that results in retrograde flow of blood (reflux) [21].

Computed tomography pulmonary angiography for assessment of pulmonary thrombosis and the pulmonary vascular aneurysm was performed. All were performed by trained staff members of the Radiology Department at Ain Shams University who were blinded to diagnosis.

A resting electrocardiogram (ECG) was also recorded for all patients.

\section{Ophthalmological assessment}

Complete ophthalmological examination were done for all the participants at the ophthalmology outpatient clinic of Ain Shams University, including assessment of their visual acuity, slit-lamp examination (for assessing the anterior chamber), and fundus examination (foe assessing retina, choroid, and optic disk).

\section{Statistical analysis}

Data were handeled using SPSS software version 20. We presented the qualitative data as frequencies and percentages and quantitative data as mean, standard deviation, range, and median. In order to compare two groups of quantitative data, we used unpaired Student's $t$ test while to examine the relationship between two qualitative variable, we used the chi-square test. For assessing the strength of association between two quantitative variables, correlation analysis was done using Pearson's method and its symbol is " $r$ " which defines both the strength and direction of linear relationship between the two variables.

We used the following criteria to determine the $p$ value significance level:

- $p$ value $<0.05$ : significant.

- $p$ value $\leq 0.001$ : highly significant.

- $p$ value $>0.05$ : insignificant.

\section{Results}

Patients' demographic and clinical characteristics

Considering demographic data, the age of the studied patients ranged between 19 and 47 years with a mean of 
$34.175 \pm 6.891$ years. There were $31(77.5 \%)$ male and nine (22.5\%) female patients with a ratio of 3.4:1 and disease duration ranged between 4 and 60 months with a mean of $21.65 \pm 15.55$ months. The distribution of cumulative clinical data among the studied patients with $\mathrm{BD}$ according to ICBD is presented in Table 1. BDCAF score among the included patients with $\mathrm{BD}$ ranged from 4 to 12 with a mean value of $7.7 \pm 2.6$ (Table 1 ).

\section{Lipid profile}

Concerning lipid profile, our study showed that 24 patients $(60 \%)$ had abnormal lipid profile distributed as follows: hypercholesterolemia was the most common found in $20(50 \%)$ patients, high level of LDL-C in $28(70 \%)$ patients, low level of HDL-C in $13(32.5 \%)$ patients, and hypertriglyceridemia in seven (17.5\%) patients (Fig. 1).

\section{The cardiovascular features}

For cardiovascular manifestations, our study showed that 45\% (18 patients) had deep vein thrombosis (DVT). 7.5\% of patients had vascular arterial lesions (two patients (5\%) had pulmonary aneurysms meanwhile one patient (2.5\%) had pulmonary thrombosis) (Table 1). Concerning ECG changes, ECHO and carotid artery duplex findings among our studied Behçet's patients are all presented in Table 2.

Table 1 Cumulative clinical data among the included Behçet's patients and disease activity score $(N=40)$

\begin{tabular}{lll}
\hline Clinical data & $\boldsymbol{N}$ & $\%$ \\
\hline Oral ulcers & 40 & 100.00 \\
Genital ulcers & 32 & 80.00 \\
Ocular manifestations & 31 & 77.50 \\
a) Anterior segment involvement & 22 & 55.00 \\
b) Posterior segment involvement & 9 & $22.5 \%$ \\
Vascular venous involvement (DVT) & 18 & 45.00 \\
Pathergy test (positive) & 11 & 27.50 \\
Neurological manifestations & 10 & 25.00 \\
a) Transient ischemic attacks & 7 & 17.50 \\
b) Hemiplegia (UMNL) & 3 & 7.50 \\
Skin lesions & 4 & 10.00 \\
a) Pseudofolliculitis & 3 & 7.50 \\
b) Erythema nodosum & 1 & 2.50 \\
Vascular arterial involvement (pulmonary) & 3 & 7.50 \\
A) Pulmonary thrombosis & 2 & 5 \\
B) Pulmonary aneurysma & 1 & 2.5 \\
BDCAF score & Range & Mean \pm SD \\
& $4-12$ & $7.7 \pm 2.6$ \\
\hline
\end{tabular}

DVT deep vein thrombosis, UMNL upper motor neuron lesion
Association of cardiovascular manifestations and disease activity as well as disease spectrum

BDCAF score was statistically significant with respect to mitral valve, tricuspid valve, and vascular venous lesions ( $p=0.004,0.034,0.002$, respectively), but not statistically significant with respect to lipid profile, ECG changes, carotid duplex changes, aortic, pulmonary valves involvement, diastolic dysfunction, intracardiac masses, and vascular arterial lesion $(p>0.05)$ (Table 3). The negative correlation between BDCAF score and left ventricular end-systolic diameter $(p=0.004)$ was significant (Fig. 2).

For comparing clincal data with lipid profile and cardiovascular manifestations, we found that a significant relation between anterior uveitis,vascular arterial, and venous involvement $(p=0.046,0.002)$, respectively; meanwhile, lipid profile was significantly related to vascular arterial affection $(p=0.027)$.

\section{Discussion}

Behçet's disease is a multi-systemic inflammatory disorder. Autoimmune factors are involved in its etiology. Immune fluorescence studies revealed IgM, IgG, and $\beta 1$ globulin on the vascular endothelial walls and the serum contained increased amounts of IgD, IgG, IgM, C1, C2, $\mathrm{C} 3, \mathrm{C} 4$, and immune complexes. The increased prevalence of the HLA-B5 tissue gene group suggests a genetic role as etiological factor [22].

Behçet's disease is a non-specific vasculitis involving both veins and arteries. Infiltration of lymphocytes, mononuclear cells, and mast cells can be observed around the blood vessels, causing endothelial swelling and fibrinoid degeneration. cardiac involvement can be seen as pericarditis, acute myocardial infarction, valve lesion, and cardiomyopathy [23].

This cross-sectional study aimed to describe the cardiovascular manifestations for patients with $\mathrm{BD}$ and its correlation with disease activity.

Varaiable cardiac manifestations are presented in our study; cardiac valvular lesion was the most common cardiac features $(67.5 \%)$. The commonest valvular lesion in this cohort was tricuspid regurgitation which was found in $27.5 \%$ of the participants, which was similar as reported by Lihong et al. where valvular affection was observed in $74.6 \%$ of patients [24]. However, aortic regurgitation was the most common valvular lesion reported by Abidov et al. in $64.9 \%$ of patients [25].

Up to date, there is no suffcient data regarding exact pathophysiology of the involvment of the heart valves that cause insufficiency among BD patients. It may be due to the inflammation that cause damage to the valve tissue which causes dilatation of both the ascending aorta and sinus valsalva aneurysm [26]

Moreover, patients with BD may also develop dilated cardiomyopathy; however, in this study, none of our 


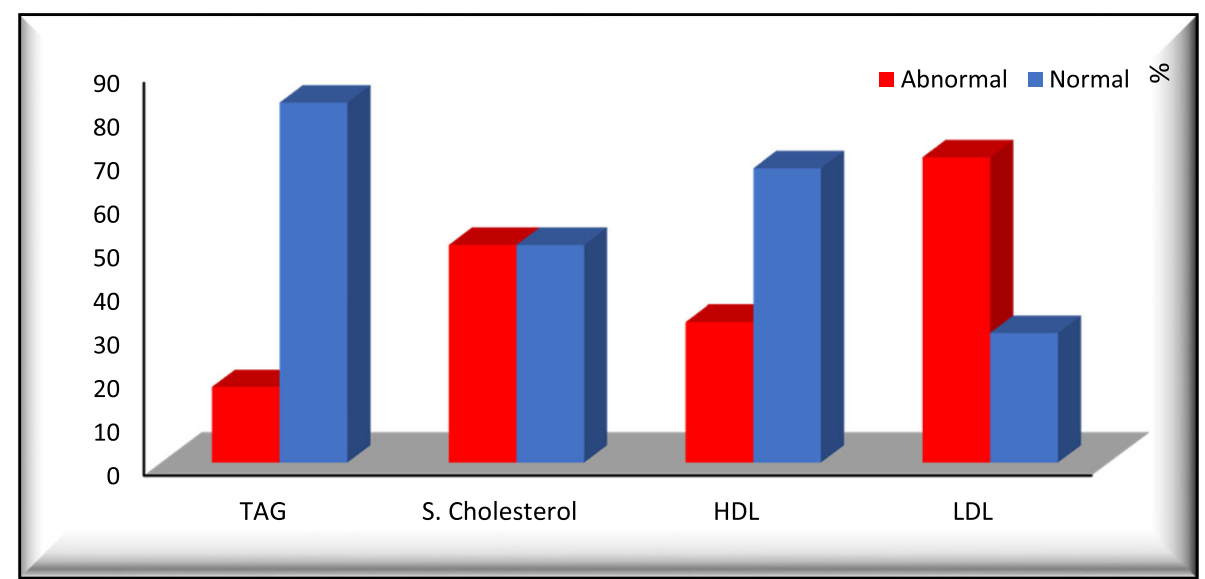

Fig. 1 Distribution of different parameters of lipid profile among included patients with Behçet's disease $(n=40)$

patients showed increased left ventricular diameter, which is disimilar to the Ulusan et al. study which found two $(5.2 \%)$ patients with increased left ventricular diameter [23].

In our study, pulmonary artery hypertension $(\mathrm{PAH})$ was present in $7.5 \%$ of patients, in contrast to Seyahi et al. where PAH was in $17 \%$ of patients [27]. These differences may be related to different numbers of patients included in the study.

Left ventricular diastolic dysfunction (LVDD) was detected in $25 \%$ of the participants, which may be considered as the most significant pathology in order to detect heart involvement in $\mathrm{BD}$. This was in agreement with the studies by Bozkurt et al. and Gemici et al. and in contrast to the study by Farouk et al. who showed that LVDD is similar in Egyptian patients with BD and healthy controls and also the study done by Tunc et al. who reported no difference btween diseased patients and healthy control regarding LVDD which may be explained by different demographic data of studied patients as regards age and disease duration [28-31].

Two of our Behçet's patients (5\%) had intracardiac masses. This was similar to the study done by Lihong et al. and Demirelli et al. [24, 32].

In our study, ECG abnormalities in the patients were as follows: left ventricular hypertrophy in (30\%), left axis deviation (27.5\%), left bundle branch block (12.5\%), and right bundle branch block (2.5\%). A lower percentage was observed in the study done by Bozkurt et al. who found that $11.1 \%$ of patients had left ventricular hypertrophy and only $1.8 \%$ had left-axis deviation; however, it is in concordance with Heper et al.'s study [28, 33].

In our study, abnormal lipid profile was found in 60\% of patients, with high total cholesterol in 50\%, high LDL$\mathrm{C}$ level in $70 \%$, abnormal lower HDL-C levels in $32.5 \%$, and high level of triglycerides in $17.5 \%$ of patients. This was in concordance with the studies by Messedi et al. and Hammami et al.; however, it is in contrast with Kayatas et al. who concluded that patients with BD in the active period may be less susceptible to atherogenic events than the controls [34-36].

We observed abnormal carotid duplex as increased IMT in $7.5 \%$ of patients. Many researches as those by Keser et al. and Hong et al. reported similar findings; however, a Korean study conducted by Rhee et al. reported no change in IMT of carotid artery in the studied patients with BD compared to controls [37-39] which may be explained by the difference between the pattern of clinical features in the Korean BD population from those in Middle East and Mediterranean regions.

In our study, vascular involvement in patients with $\mathrm{BD}$ was either arterial or venous (52.5\%). The ratio was within proximity to many studies, as by El Mallahr et al. (39\%) and El-Garfa et al. (58.9\%); however, it is higher than that by Skef et al. (7-29\%) [40-42].

Vascular lesions mainly consist in venous and arterial thrombosis and various types of arterial aneurysms. Venous lesions were more common in our cohort and reported in $45 \%$, which is in agreement with Düzgün et al. findings which demonstrated that venous lesions are reported in 37.7\%; however, Ulusan et al. reported only three cases $(7.8 \%)$ with lower limb DVT [23, 43].

Arterial involvement was less common and found in only three $(7.5 \%)$ patients in this cohort (two had pulmonary aneurysm [5\%] and only one had pulmonary thrombosis $[2.5 \%])$. These findings were in agreement with the results obtained by Düzgün et al. who found them as 1.6\%; however, El Mallahr et al. found that arterial affection was $17 \%[40,43]$.

In our study, the BDCAF score was compared to multiple cardiovascular parameters where we found that it was significantly related to the mitral valve, tricuspid valve, and vascular venous affection $(p=0.004,0.034$, and 0.002), respectively. This was in concordance with 
Table 2 Findings of ECG, carotid Doppler, and echocardiography among included Behçet's patients $(N=40)$

\begin{tabular}{|c|c|c|c|}
\hline \multicolumn{2}{|l|}{ ECG findings } & \multirow{2}{*}{$\begin{array}{l}N \\
11\end{array}$} & \multirow{2}{*}{$\begin{array}{l}\% \\
27.50\end{array}$} \\
\hline Axis deviation & Left & & \\
\hline & Right & 0 & 0 \\
\hline \multirow[t]{2}{*}{ Ventricular hypertrophy } & Left & 12 & 30.00 \\
\hline & Right & 0 & 0 \\
\hline \multirow[t]{2}{*}{ Bundle Branch block } & Right & 1 & 2.50 \\
\hline & Left & 5 & 12.50 \\
\hline Carotid artery parameters & & $N$ & $\%$ \\
\hline \multirow[t]{2}{*}{ Carotid duplex } & $\begin{array}{l}\text { Abnormal (increased IMT) carotid } \\
\text { atherosclerotic vascular disease }\end{array}$ & 3 & 7.50 \\
\hline & Normal & 37 & 92.50 \\
\hline \multirow[t]{2}{*}{ Carotid IMT (mm) } & Range & 0.5 & \\
\hline & Mean \pm SD & 0.78 & \\
\hline \multicolumn{4}{|l|}{ Echocardiography parameters } \\
\hline \multirow[t]{2}{*}{ Ejection fraction } & Range & $56-$ & \\
\hline & Mean \pm SD & 65.5 & \\
\hline \multirow[t]{2}{*}{ RVSP $(\mathrm{mmHg})$} & Range & $20-$ & \\
\hline & Mean \pm SD & 25. & \\
\hline \multirow[t]{2}{*}{ Left ventricular end systolic diameter (mm) } & Range & 24 & \\
\hline & Mean \pm SD & 30. & \\
\hline \multirow[t]{2}{*}{ Left ventricular end diastolic diameter $(\mathrm{mm})$} & Range & 39 & \\
\hline & Mean \pm SD & 47. & \\
\hline \multirow[t]{2}{*}{ Interventricular septum diameter $(\mathrm{mm})$} & Range & $7-$ & \\
\hline & Mean \pm SD & 8.50 & \\
\hline \multirow[t]{2}{*}{ Left atrial diameter $(\mathrm{mm})$} & Range & 28 & \\
\hline & Mean \pm SD & 33.8 & \\
\hline \multirow[t]{2}{*}{ Pulmonary artery pressure $(\mathrm{mmHg})$} & Range & 12 & \\
\hline & Mean \pm SD & 17. & \\
\hline \multicolumn{2}{|c|}{ Valves, aortic root, and right ventricular systolic diameters } & $N$ & $\%$ \\
\hline Aortic valve & AR & 4 & 10.00 \\
\hline Mitral valve & MR & 7 & 17.50 \\
\hline Tricuspid valve & TR & 11 & 27.50 \\
\hline Pulmonary valve & PR & 5 & 12.50 \\
\hline Tricuspid and pulmonary valve & TR and PR & 3 & $7.5 \%$ \\
\hline Mitral and tricuspid valve & MR and TR & 4 & $10 \%$ \\
\hline Mitral, tricuspid, and pulmonary valve & $M R, T R$, and PR & 2 & $5 \%$ \\
\hline Aortic root diameter & Normal & 40 & 100.00 \\
\hline Right ventricular systolic diameter & Normal & 40 & 100.00 \\
\hline \multicolumn{2}{|l|}{ Other abnormalities } & $N$ & $\%$ \\
\hline Diastolic dysfunction & Positive & 10 & 25.00 \\
\hline Pulmonary artery pressure & Increase & 3 & $7.5 \%$ \\
\hline Pericardium & Normal & 40 & $100 \%$ \\
\hline Intracardiac masses & Positive & 2 & $5.00 \%$ \\
\hline
\end{tabular}

ECG electrocardiogram, $R V S P$ right ventricular systolic pressure, $A R$ aortic regurgitation, $T R$ tricuspid regurgitation, $M R$ mitral regurgitation, $P R$ pulmonary regurgitation, $S D$ standard deviation 
Table 3 Comparisons of Behçet patients with different cardiovascular characteristics regarding disease activity score

\begin{tabular}{|c|c|c|c|c|c|}
\hline \multirow[t]{2}{*}{ Cardiovascular parameters and lipid profile } & & \multicolumn{2}{|c|}{ BDCAF score } & \multicolumn{2}{|c|}{$T$ test or ANOVA } \\
\hline & & $N$ & Mean \pm SD & $T$ or $F$ & $p$ value \\
\hline \multirow[t]{2}{*}{ Lipid profile } & Abnormal & 24 & $7.500 \pm 1.934$ & -0.814 & 0.421 \\
\hline & Normal & 16 & $8.188 \pm 3.410$ & & \\
\hline \multirow[t]{2}{*}{ Axis deviation } & Negative & 29 & $7.862 \pm 2.850$ & 0.339 & 0.736 \\
\hline & Left & 11 & $7.545 \pm 1.916$ & & \\
\hline \multirow[t]{2}{*}{ Ventricular hypertrophy } & Negative & 28 & $7.643 \pm 2.642$ & -0.485 & 0.631 \\
\hline & Left & 12 & $8.083 \pm 2.610$ & & \\
\hline \multirow[t]{3}{*}{ Bundle branch block } & Negative & 34 & $7.735 \pm 2.678$ & 0.367 & 0.695 \\
\hline & Right & 1 & $6.000 \pm 0.000$ & & \\
\hline & Left & 5 & $8.400 \pm 2.408$ & & \\
\hline \multirow[t]{2}{*}{ Carotid duplex } & Abnormal & 3 & $7.667 \pm 0.577$ & -0.074 & 0.941 \\
\hline & Normal & 37 & $7.784 \pm 2.709$ & & \\
\hline \multirow[t]{2}{*}{ Aortic valve } & AR & 4 & $9.500 \pm 1.732$ & 1.413 & 0.166 \\
\hline & Normal & 36 & $7.583 \pm 2.634$ & & \\
\hline \multirow[t]{2}{*}{ Mitral valve } & MR & 7 & $10.286 \pm 3.592$ & 3.100 & $0.004^{*}$ \\
\hline & Normal & 33 & $7.242 \pm 2.047$ & & \\
\hline \multirow[t]{2}{*}{ Tricuspid valve } & TR & 11 & $9.182 \pm 3.125$ & 2.204 & $0.034^{*}$ \\
\hline & Normal & 29 & $7.241 \pm 2.214$ & & \\
\hline \multirow[t]{2}{*}{ Pulmonary valve } & PR & 5 & $7.000 \pm 1.581$ & -0.706 & 0.484 \\
\hline & Normal & 35 & $7.886 \pm 2.720$ & & \\
\hline \multirow[t]{2}{*}{ Diastolic dysfunction } & Positive & 10 & $8.700 \pm 3.302$ & 1.308 & 0.199 \\
\hline & Negative & 30 & $7.467 \pm 2.315$ & & \\
\hline \multirow[t]{2}{*}{ Intra cardiac masses } & Positive & 2 & $6.000 \pm 1.414$ & -0.988 & 0.330 \\
\hline & Negative & 38 & $7.868 \pm 2.632$ & & \\
\hline \multirow[t]{2}{*}{ Vascular arterial affection (pulmonary) } & Positive & 3 & $8.667 \pm 4.726$ & 0.611 & 0.545 \\
\hline & Negative & 37 & $7.703 \pm 2.459$ & & \\
\hline \multirow[t]{2}{*}{ Vascular venous affection } & Positive & 18 & $9.111 \pm 2.610$ & 3.279 & $0.002^{*}$ \\
\hline & Negative & 22 & $6.682 \pm 2.079$ & & \\
\hline
\end{tabular}

ANOVA analysis of variance, BDCAF Behçet's Disease Current Activity Form, AR aortic regurgitation, $M R$ mitral regurgitation, $T R$ tricuspid regurgitation, $P R$ pulmonary regurgitation, $S D$ standard deviation

*significant

Eldin and Ibrahim's study [44]. These results reflected the importance of cardiovascular features as predictor paramters of disease activity score.

We found a significant negative correlation between BDCAF score and left ventricular end-systolic diameter (LVDD) $(p=0.004)$. Similar results were found in an Egyptian study conducted by Hassan and Ebaid who demonstrated a significant correlation between BDCAF and different echocardiographic parameters as LVDD and systolic and diastolic dysfunction [12]. Also, Ikonomidis et al. found BD with vascular complication to have more myocardial and aortic wall dysfunction and attributed this to a common pathophysiologic pathway that may elevate inflammatory cytokines as interleukin-2 (IL-2) and IL-6 [45].

These findings revealed that systolic function impaired even before the development of overt cardiac failure may be due to early affection of subendocardial longitudinal fibers with no distortion in circumferential function in $\mathrm{BD}$ due to the deterioration in coronary microvascular function, which is attributed to small vessel vasculitis [46].

Our study demonstrated a significant relationship between lipid profile and vascular arterial involvement $(p=0.027)$ in this cohort and which was similar to the results of the studies by Ricart et al. and Musabak et al. who related increase of lipoprotein to the athero-thrombotic event in BD patients [47, 48].

We found a significant relationship between anterior uveitis and vascular involvement (either arterial or venous) ( $p=0.046,0.002)$ respectively, which was similar to results reported by $\mathrm{Yu}$ et al. who concluded that the presence of vascular thrombosis is one of the bad prognostic factors of uveitis in BD patients; however, 


$$
r=-0.449 \quad \text { P-value }=0.004^{*}
$$

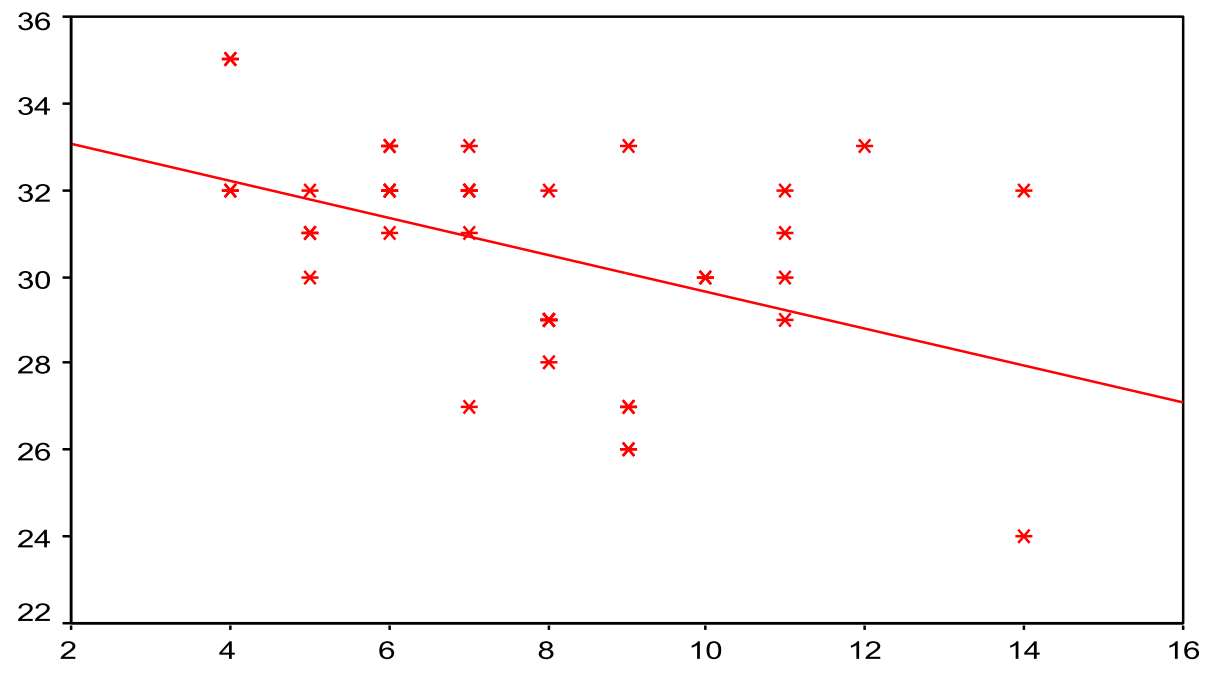

\section{BDCAF Score}

Fig. 2 Correlation between Behçet's Disease Current Activity Form (BDCAF) score and left ventricular end-systolic diameter

Houman et al. reported the less frequent occurrence of DVT as well as a genital ulcer in patients with ocular involvement $[49,50]$.

\section{Conclusion}

Cardiovascular complications are significantly frequent among patients with $\mathrm{BD}$, although asymptomatic; therefore, these complications must be screened for early detection and proper management to improve prognosis, quality of life and decrease the morbidity and mortality of the disease.

\section{Abbreviations}

BD: Behçet's disease; BDCAF: Behçet's Disease Current Activity Form; ICBD: International Criteria for Behçet's Disease; IMT: Intimal medial thickness; HDL-C: High-density lipoprotein cholesterol; LDL-C: Low-density lipoprotein cholesterol; ECG: Electrocardiogram.; ECHO: Echocardiography; PAH: Pulmonary artery hypertension; LV: Left ventricular; LVDD: Left ventricular diastolic dysfunction; TDI: Tissue Doppler imaging; EF: Ejection fraction; ASE: American Society of Echocardiography; RV: Right ventricular; FAC: Fractional area change; TAPSE: Tricuspid annular plane systolic excursion; LVOT: Left ventricular outflow tract diameter; PE: Pericardial effusion; DVT: Deep venous thrombosis; CBC: Complete blood count: ESR: Erythrocyte sedimentation rate; CRP: C-reactive protein; BUN: Blood urea nitrogen; AST: Aspartate aminotransferase; ALT: Alanine aminotransferase

\section{Acknowledgements}

Great thanks to all participants in this work, supervisors, and all authors for their effort in the research production.

\section{Authors' contributions}

NM conceived the idea and planned the research work. DF contributed to the design, supervised the finding, verified the analytic methods, and reviewed the manuscript. FB participated in writing the research, performed part of investigations, and supervised the work. MT carried out the data collection, statistical analysis, and writing and contributed to the work planning, data analysis, and manuscript writing. All authors discussed the result and contributed to the final manuscript. The authors read and approved the final manuscript.

\section{Funding}

This research did not receive any specific grant from funding agencies in the public, commercial, or not-for-profit sectors.

\section{Availability of data and materials}

The datasets used and/or analyzed during the current study are available from the corresponding author on reasonable request.

\section{Declarations}

Ethics approval and consent to participate

This study was approved by the local research ethical committee of the Faculty of Medicine at Ain Shams University in Egypt, reference number: FWA000017585 (No: FMASU 124/2019). All patients included in this study gave written informed consent to participate in this research.

\section{Consent for publication}

Consent for publication was taken from all participants.

\section{Competing interests}

The author(s) declare no potential conflicts of interest concerning the research, authorship, and/or publication of this manuscript.

Received: 19 February 2021 Accepted: 26 April 2021

Published online: 04 May 2021

\section{References}

1. Yazici H, Seyahi E, Hatemi G, Yazici Y (2018) Behçet syndrome: a contemporary view. Nat Rev Rheumatol 14(2):107-119. https://doi.org/10.1 038/nrrheum.2017.208

2. Aslam F, Bandeali SJ, Crowson C, Alam M. (2016) Cardiac function and diastolic dysfunction in Behcet's disease: A systematic review and metaanalysis. Int J Rheumatol. Article ID 9837184. https://doi.org/10.1155/2 $016 / 9837184$

3. Farouk H, Chilali KE, Said K, Sakr B, Salah H, Mahmoud G, Sorour K (2014) Value of certain echocardiographic findings in the initial suspicion of Behcet's disease. Echocardiography. 31(8):924-930. https://doi.org/10.1111/echo.12601

4. Song JK, Kim MJ, Kim DH, Song JM, Kang DH, Lee I, Lee SK, Yoo B (2011) Factors determining outcomes of aortic valve surgery in patients with aortic regurgitation due to Behcet's disease: impact of preoperative echocardiographic features. J Am Soc Echocardiogr 24(9):995-1003. https:// doi.org/10.1016/j.echo.2011.06.006 
5. Marzban M, Mandegar MH, Karimi A, Abbasi K, Movahedi N, Navabi MA, Abbasi SH, Moshtaghi N (2008) Cardiac and great vessel involvement in 'Behcet's disease. J Card Surg 23(6):765-768. https://doi.org/10.1111/j.15408191.2008.00607.x

6. Geri G, Wechsler B, Huong Du LT, Piette JC, Amoura Z, Resche-Rigon M et al (2012) Spectrum of cardiac lesions in Behcet disease: a series of 52 patients and review of the literature. Medicine (Baltimore) 91(1):25-34. https://doi. org/10.1097/MD.0b013e3182428f49

7. Kuzu MA, Ozaslan C, Köksoy C, Gürler A, Tüzüner A (1994) Vascular involvement in Behçet's disease: 8-year audit. World J Surg 18(6):948-953. https://doi.org/10.1007/BF00299119

8. La Regina M, Gasparyan AY, Orlandini F, Prisco D (2010) Behçet's disease as a model of venous thrombosis. Open Cardiovasc Med J 4:71-77

9. Owlia MB, Mehrpoor G (2012) Behcet's disease: New concepts in cardiovascular involvements and future direction for treatment. ISRN Pharmacol. Article ID 760484. https://doi.org/10.5402/2012/760484

10. Badr Eldin A, Ibrahim A (2014) Assessment of the relationship between vascular endothelial growth factor and cardiovascular involvement in Egyptian patients with Behçet's disease. Egypt Rheumatol 36:131-137

11. Hassan S, Gheita T, Ghoneim S, Nasr L (2012) Subclinical atherosclerosis in Behçet's disease. Turk J Rheumatol 27(2):109-114. https://doi.org/10.5606/ tjr.2012.016

12. Hassan WA, Ebaid HH (2016) Assessment of left ventricular function and aortic elastic properties in patients with Behçet's disease using conventional and tissue Doppler echocardiography. Egypt Rheumatol 38:47-52

13. Davatchi F, Assaad-Khalil S, Calamia KT, Crook JE, Sadeghi-Abdollahi B, Schirmer M et al (2014) International Team for the Revision of the International Criteria for Behçet's Disease (ITR-ICBD). The International Criteria for Behçet's Disease (ICBD): a collaborative study of 27 countries on the sensitivity and specificity of the new criteria. J Eur Acad Dermatol Venereol 28:338-347

14. Expert Panel (2001) Executive summary of the third report of the National Cholesterol Education Program (NCEP) Expert Panel on Detection, Evaluation, and Treatment of High Blood Cholesterol in Adults (Adult Treatment Panel III). J Am Med Assoc 285:2486-2497

15. Choi HJ, Seo MR, Ryu HJ, Baek HJ (2015) Cross-cultural adaptation and validation of the Behcet's disease current activity form in Korea. Korean J Intern Med 30(5):714-718. https://doi.org/10.3904/kjim.2015.30.5.714

16. Lang RM, Bierig M, Devereux RB, Flachskampf FA, Foster E, Pellikka PA et al (2005) Recommendations for chamber quantification: a report from the American Society of Echocardiography's Guidelines and Standards Committee and the Chamber Quantification Writing Group, developed in conjunction with the European Association of Echocardiography, a branch of the European Society of Cardiology. J Am Soc Echocardiogr 18:1440-1463

17. Paulus WJ, Tschope C, Sanderson JE, Rusconi C, Flachskampf FA, Rademakers FE et al (2007) How to diagnose diastolic heart failure: a consensus statement on the diagnosis of heart failure with normal left ventricular ejection fraction by the Heart Failure and Echocardiography Associations of the European Society of Cardiology. Eur Heart J 28(20):2539 2550. https://doi.org/10.1093/eurheartj/ehm037

18. Rudski LG, Lai WW, Afilalo J, Hua L, Handschumacher MD, Chandrasekaran K et al (2010) Guidelines for the echocardiographic assessment of the right heart in adults: a report from the American Society of Echocardiography endorsed by the European Association of Echocardiography, a registered branch of the European Society of Cardiology, and the Canadian Society of Echocardiography. J Am Soc Echocardiogr 23:685-713

19. Mohan V, Ravikumar R, Shanthi Rani S, Deepa R (2000) Intimal medial thickness of the carotid artery in South Indian diabetic and non-diabetic subjects: The Chennai Urban Population Study. Diabetologia. 43(4):494-499. https://doi.org/10.1007/s001250051334

20. Touboul P-J, Hennerici MG, Meairs S, Adams H, Amarenco P, Bornstein N, Csiba L, Desvarieux M, Ebrahim S, Fatar M, Hernandez Hernandez R, Jaff M, Kownator S, Prati P, Rundek T, Sitzer M, Schminke U, Tardif JC, Taylor A, Vicaut E, Woo KS, Zannad F, Zureik M (2007) Mannheim carotid intimamedia thickness consensus (2004-2006). Cerebrovasc Dis 23(1):75-80. https://doi.org/10.1159/000097034

21. Khilnani NM (2012) Duplex ultrasound evaluation of patients with chronic venous disease of the lower extremities. AJR Am J Roentgenol 202(3):633-642

22. Baharav E, Weinberger A (2012) The HLA-B*5101 molecule-binding capacity to antigens used in animal models of Behçet's disease: a bio-informatics study. Med Assoc J 4(7):424-428
23. Ulusan Z, Karadag AS, Tasar M, Kalender M, Darcin OT (2014) Behcet's disease and cardiovascular involvement: our experience of asymptomatic Behcet's patients. Cardiovasc J Afr 25(2):63-66. https://doi.org/10.5830/CVJA-2014-003

24. Lihong P, Li R, Xie J, Liu G, Yang Y (2017) A giant pseudoaneurysm of coronary artery in a young patient with Behçet's disease. Echocardiography 34:1736-1737

25. Abidov A, Alpert JS (2014) Importance of echocardiographic findings in the acute presentation of Behcet's disease-diagnostic and prognostic considerations. Echocardiography 31(8):913-915. https://doi.org/10.1111/echo.12659

26. Lee CW, Lee JS, Lee WK, Lee CH, Suh CH, Song CH, Park YB, Lee SK, Won YS (2002) Aortic valve involvement in Behcet's disease. A clinical study of 9 patients. Korean J Intern Med 17(1):51-56. https://doi.org/10.3904/kjim.2002.17.1.51

27. Seyahi E, Baskurt M, Melikoglu M, Akman C, Olgun DC, Simsek E, Hamuryudan V, Kucukoglu S, Yazici H (2011) The estimated pulmonary artery pressure can be elevated in Behçet's syndrome. Respir Med 105(11): 1739-1747. https://doi.org/10.1016/j.rmed.2011.07.022

28. Bozkurt A, Akpınar O, Uzun S, Akman A, Arslan D, Birand A (2006) Echocardiographic findings in patients with Behçet's disease. Am J Cardiol 97(5):710-715. https://doi.org/10.1016/j.amjcard.2005.09.120

29. Gemici K, Baran I, Güllülü S, Kazazoglu AR, Cordan J, Ozer Z (2000) Evaluation of diastolic dysfunction and repolarization dispersion in Behcet's disease. Int J Cardiol 73(2):143-148. https://doi.org/10.1016/S0167-5273(00)00175-3

30. Farouk H, Zayed HS, Mahmoud G (2016) Assessment of left ventricular diastolic function in Egyptian patients with Behçet's disease. Arch Rheumatol 31(2):151-157. https://doi.org/10.5606/ArchRheumatol.2016.5777

31. Tunc SE, Dogan A, Gedikli O, Arslan C, Sahin M (2005) Assessment of aortic stiffness and ventricular diastolic functions in patients with Behçet's disease. Rheumatol Int 25(6):447-451. https://doi.org/10.1007/s00296-004-0558-6

32. Demirelli S, Degirmenci H, Inci S, Arisoy A (2015) Cardiac manifestations in Behcet's disease. Intractable Rare Dis Res 4(2):70-75. https://doi.org/10.5582/ irdr.2015.01007

33. Heper G, Polat M, Yetkin E, Senen K (2010) Cardiac findings in Behçet's patients. Int J Dermatol 49(5):574-578. https://doi.org/10.1111/j.1365-4632.2 010.04424.x

34. Messedi M, Jamoussi K, Frigui M, Laporte F, Turki M, Chaabouni K, Mnif E, Jaloulli M, Kaddour N, Bahloul Z, Ayedi F (2011) Atherogenic lipid profile in Behcet's disease: evidence of alteration of HDL subclasses. Arch Med Res 42(3):211-218. https://doi.org/10.1016/j.arcmed.2011.05.001

35. Hammami S, Ben Yahia S, Mahjoub S, Khairallah M (2006) Orbital inflammation associated with Behcet's disease. Clin Exp Ophthalmol 34(2): 188-190. https://doi.org/10.1111/j.1442-9071.2006.01181.x

36. Kayatas K, Karatoprak C, Cebeci F, Dayan A, Ozkan S, Pehlevan SM, Kartal I, Demirtunc R (2013) Presence of low lipid levels in patients with Behcet's disease as a protector against atherosclerosis. Eur Rev Med Pharmacol Sci 17(17):2330-2334

37. Keser G, Aksu K, Tamsel S, Ozmen M, Kitapcioglu G, Kabaroglu C et al (2005) Increased thickness of the carotid artery intima-media assessed by ultrasonography in Behcet's disease. Clin Exp Rheumatol 23(Suppl 38):71-76

38. Hong SN, Park JC, Yoon NS, Kim KH, Hong YJ, Park HW et al (2008) Carotid artery intima-media thick-ness in Behcet's disease patients without significant cardiovascular involvement. Korean J Intern Med 23(2):87-93. https://doi.org/10.3904/kjim.2008.23.2.87

39. Rhee MY, Chang HK, Kim SK (2007) Intima-media thickness and arterial stiffness of carotid artery in Korean patients with Behcet's disease. J Korean Med Sci 22(3):387-392. https://doi.org/10.3346/jkms.2007.22.3.387

40. El Mallahr R, Abdo M, Alkemary A (2019) What is the impact of traditional risk factors for vascular affection on Behcet's disease vascular involvement: a retrospective cohort study? Egypt Rheumatol Rehabil 46:257

41. El-Garfa AK, Abdoa M, Alkemaryb A, Mohamed S (2019) Behçet's disease patterns and subsets in a cohort of Egyptian patients. Egypt Rheumatol 41(2):135-138. https://doi.org/10.1016/j.ejr.2018.05.006

42. Skef W, Hamilton MJ, Arayssi T (2015) Gastrointestinal Behçet's disease: a review. World J Gastroenterol 21(13):3801-3812. https://doi.org/10.3748/wjg. v21.i13.3801

43. Düzgün N, Küçükşahin O, Atasoy KÇ, Togay Işıkay C, Gerede DM, Erden A, et al (2013) Behçet's Disease and Intracardiac Thrombosis: A Report of Three Cases. Case Rep Rheumatol. Article ID 637015. https://doi.org/10.1155/2013/637015

44. Eldin AB, Ibrahim A (2014) Assessment of the relationship between vascular endothelial growth factor and cardiovascular involvement in Egyptian patients with Behcet's disease. Egypt Rheumatol 36(3):131-137. https://doi. org/10.1016/j.ejr.2013.12.006 
45. Ikonomidis I, Lekakis J, Stamatelopulos K, Markomihelakis N, Kaklamanis PG, Mavrikakis M (2004) Aortic elastic properties and left ventricular diastolic function in patients with Adamantiades. Behçet's Dis J AM Coll Cordial 43(6):1075-1081. https://doi.org/10.1016/j.jacc.2003.10.042

46. Yagmur, Sener S, Acikgoz N, Cansel M, Ermis N, Karincaoglu Y et al (2011) Subclinical left ventricular dysfunction in Behçet's disease assessed by twodimensional speckle tracking echocardiography. Eur J Echocardiogr 12(7): 536-541. https://doi.org/10.1093/ejechocard/jer088

47. Ricart JM, Vaya A, Santaolaria M, España F, Aznar J (2006) Dyslipidaemia in Behcet's disease as a thrombotic risk factor. Ann Rheum Dis 65(9):12481249. https://doi.org/10.1136/ard.2005.049551

48. Musabak U, Baylan O, Cetin T, Yesilova Z, Sengul A, Saglam K, Inal A, Kocar IH (2005) Lipid profile and anticardiolipin antibodies in Behcet's disease. Arch Med Res 36(4):387-392. https://doi.org/10.1016/j.arcmed.2005.03.019

49. Yu HG, Kim MJ, Sewoong F (2009) Fluorescein angiography and visual acuity in active uveitis with Behçet disease. Ocul Immunol Inflamm 17(1): 41-46. https://doi.org/10.1080/09273940802553279

50. Houman MH, Neffati $\mathrm{H}$, Braham A, Harzallah O, Khanfir M, Miled M et al (2007) Behçet's disease in Tunisia. Demographic, clinical and genetic aspects in 260 patients. Clin Exp Rheumatol 25:58-64

\section{Publisher's Note}

Springer Nature remains neutral with regard to jurisdictional claims in published maps and institutional affiliations.

\section{Submit your manuscript to a SpringerOpen ${ }^{\circ}$ journal and benefit from:}

- Convenient online submission

- Rigorous peer review

- Open access: articles freely available online

High visibility within the field

- Retaining the copyright to your article

Submit your next manuscript at $\boldsymbol{\nabla}$ springeropen.com 